\title{
COLABORADORES DESTE NÚMERO E PARECERISTAS AD. HOC.
}

\section{COORDENADORAS DO DOSSIÊ: \\ Estudos sobre da língua inglesa: ensino e outras perspectivas}

\section{RENATA PHILIPPOV}

Possui bacharelado em Letras (Português/Inglês/Francês) pela Universidade de São Paulo (1994), licenciatura em Letras (Português/Inglês/Francês) pela Universidade de São Paulo (1995), mestrado em Letras (Língua e Literatura Francesa) pela Universidade de São Paulo (1999), doutorado em Letras pela Universidade de São Paulo (2005) e pós-doutorado em Linguística Aplicada pelo LAEL/PUCSP (2015). Tem experiência na área de Letras, com ênfase em Línguas e Literaturas Estrangeiras Modernas, atuando principalmente nos seguintes temas: língua inglesa, literaturas de língua inglesa, metodologia de ensino, formação docente, gestão curricular integrada, Edgar Allan Poe, Charles Baudelaire, Machado de Assis, estudos de recepção literária e literatura comparada. Atualmente desenvolve projeto de pesquisa sobre a recepção crítica da obra de Edgar Allan Poe na obra de Machado de Assis, pelo viés da literatura fantástica. É credenciada no Programa de Mestrado em Letras da UNIFESPcampus Guarulhos. É membro do GT Vertentes do Insólito Ficcional da Anpoll e líder do grupo de pesquisa Língua e Literatura: interdisciplinaridade e docência (CNPq).

\section{VERA LÚCIA HARABAGI HANNA}

Doutora na Área de Historiografia Linguística do Programa de Estudos PósGraduados em Língua Portuguesa da Pontifícia Universidade Católica de São Paulo com pesquisa sobre aspectos culturais e linguísticos da londonização do Brasil no século XIX - o hibridismo cultural em João do Rio. É Mestre no Programa de Educação, Arte e História da Cultura pela Universidade Presbiteriana Mackenzie. É professora adjunta do Programa de Pós-Graduação em Letras da Universidade Presbiteriana Mackenzie e atua no Curso de Graduação em Letras do Centro de Comunicação e Letras da UPM com disciplinas sobre Metodologia de Ensino de Língua Inglesa, Cultura dos Povos de Língua Inglesa e Estudos Culturais. É Membro do GT Historiografia Linguística da Associação Nacional de Pesquisa em Letras e Linguística (ANPOLL) e pesquisadora convidada do IP-PUC/SP (Instituto de Pesquisas Lingüísticas Sedes Sapientiae) - da Pontifícia Universidade Católica de São Paulo). É Pesquisadora-líder do $\mathrm{CNPq}$ do grupo Praticando estudos culturais: língua, cultura e texto no ensino de línguas estrangeiras. Coordena o projeto de 
pesquisa Diálogos transdisciplinares nas Letras: línguas estrangeiras, cultura e comunicação do PPGL da UPM. Dedica-se, também, à área dos Estudos Americanos e foi presidente da ABEA (Associação Brasileira de Estudos Americanos) no período de 2005 - 2007. Destacam-se em sua produção palestras, organizações de eventos, publicações de livros, capítulos, e em periódicos nacionais e internacionais, em que desenvolve linhas de pesquisa vinculadas aos Estudos Culturais, aos Estudos Americanos, à Metodologia de Ensino de Línguas Estrangeiras, à Transdisciplinaridade, trabalhando conceituações relativas a questões identitárias, hibridização cultural, cruzamento de fronteiras, interculturalidade, pós-colonialismo, dentre outras, a partir da reflexão em textos de múltiplas linguagens, em diferentes contextos, também em intersecção com o Ensino de Línguas Estrangeiras. Participa de Conselhos Editoriais de Revistas especializadas nacionais e esttrangeiras e atua, igualmente, como parecerista ad hoc. Desde 2010 é editora-executiva dos Cadernos de Pós-Graduação em Letras do PPGL da UPM. Dentre suas mais recentes publicações estão o livro Línguas Estrangeiras: o ensino em um contexto cultural, da Coleção Conexão Inicial (2012), e a organização do volume Letras no Terceiro Milênio: diálogos transdisciplinares (2015), ambos da Editora Mackenzie.

\section{PARECERISTAS AD. HOC.:}

\section{ANA LUIZA RAMAZZINA}

Professora Adjunta 3 na área de língua e literatura francesa do departamento de letras da Escola de Filosofia, Letras e Ciências Humanas da Universidade Federal de São Paulo, possui mestrado e doutorado em Língua e Literatura francesa pela Universidade de São Paulo e pós-doutorado com pesquisa em estudos da tradução (em sua relação com o ensino) no Instituto de Estudos da Linguagem (IEL), UNICAMP. Atua na área de Letras, com ênfase no ensino de FLE, e nas estratégias de construção da linguagem literária. É credenciada no Programa de Mestrado em Letras da UNIFESP - campus Guarulhos. É líder do grupo de pesquisa Língua e Literatura: interdisciplinaridade e docência (CNPq). Sua pesquisa mais recente tem se voltado, sobretudo, às relações entre língua e linguagens, estrutura literária e estruturas linguísticas no ensino de FLE, além do impacto dos conceitos de multimodalidade e de intermidialidade sobre noções tradicionais de língua.

\section{CLEYDSTONE CHAVES DOS SANTOS}


Possui graduação em Letras Estrangeiras Modernas Inglês pela UFPB (1999), Francês pela UFCG (2004), mestrado em Letras pela UFPB (2006) e doutorado em Estudos da Tradução pela UFSC (2014). Também tem formação linguística em alemão e espanhol pela UFCG. E alemão Fernstudium (UFBA- Goethe Institut). Atualmente é Professor Adjunto I, lotado na Unidade Acadêmica de Letras - UAL na UFCG. Tem experiência na área de Letras com ênfase em linguística aplicada, atuando nos seguintes temas: novas tecnologias no processo ensino-aprendizagem de língua estrangeira sob uma perspectiva sociocultural; e o papel da língua materna no processo ensino-aprendizagem de língua estrangeira. Também é pesquisador em Estudos da Tradução/Tradução Automática (TA) focando em pontos que dialogam a TA com os seguintes eixos temáticos: Linguagem controlada no texto fonte; Comparação com Sistemas de TA; Comparação com Tradução Humana; e Aplicações no Ensino de Línguas Estrangeiras.

\section{JOSÉ HAMILTON MARUXO JUNIOR}

Doutor, Mestre e Licenciando pela FFLCH-USP. Graduado em Letras Francês e Português - pela Universidade de São Paulo. Fez mestrado em língua e literatura francesa na Universidade de São Paulo, tendo analisado a constituição irônica e seu papel argumentativo em gêneros da imprensa quotidiana, em publicações brasileiras e francesas. Na tese de doutoramento, também concluída na Universidade de São Paulo, continuou estudando a problemática da argumentação em textos de imprensa, com ênfase na análise dos textos de divulgação/vulgarização científica. Tem experiência como professor de língua portuguesa e de língua francesa, no ensino básico e superior, com mais de dez anos de atuação em escolas públicas e privadas de São Paulo. Desenvolveu trabalhos de assessoria e consultoria na área de língua portuguesa e na produção de livros e manuais didáticos. Autor de várias obras voltadas para o ensino de língua portuguesa. Atualmente é Professor Adjunto da Escola de Filosofia, Letras e Ciências Humanas da Universidade Federal de São Paulo (UNIFESP).

\section{LUCIENE MARIA PATRIOTA}

Possui Graduação em Licenciatura Plena em Letras pela Universidade Federal da Paraíba (1993), Especialização em Linguística Aplicada ao Ensino pela 
Universidade Federal de Campina Grande (2002), Mestrado em Linguagem e Ensino pela Universidade Federal de Campina Grande (2006) e Doutorado em Linguística pela Universidade Federal da Paraíba (2011). Tem experiência na área de Letras, com ênfase em Letras, atuando principalmente nos seguintes temas: gíria, livro didático, ensino e língua. Professora Adjunta da UFCG (2013). Atualmente coordena o Programa de Monitoria da Unidade Acadêmica de Letras (UFCG).

\section{PAULO ROBERTO MASSARO}

É Licenciado em Letras (Francês/Português), Mestre e Doutor em Letras (Língua e Literatura Francesa) pela Faculdade de Filosofia, Letras e Ciências Humanas da Universidade de São Paulo (FFLCH-USP), onde atua, desde julho de 2006, como docente de Língua Francesa na Habilitação Francês e no Programa de Pós-Graduação em Estudos Linguísticos, Literários e Tradutológicos em Francês. É membro do grupo de pesquisa Língua e Literatura: interdisciplinaridade e docência, sediado na Universidade Federal de São Paulo (UNIFESP). Sua experiência profissional abrange o ensino de Francês, Língua Estrangeira e suas relações com a Linguagem Teatral, de Francês com Objetivos Específicos e de Francês com Objetivos Acadêmicos. De 2000 a 2006, atuou como docente responsável por disciplinas de Francês Geral e de Francês com Objetivos Específicos e Acadêmicos no Centro de Ensino de Línguas da Universidade Estadual de Campinas (CEL-Unicamp) e de 2002 a 2003 no Bacharelado em Secretariado Executivo Trilíngue da Universidade Estadual de Maringá (UEM). Autor do livro Teatro e Língua Estrangeira, entre teoria(s) e prática(s), tem oferecido oficinas e cursos de formação continuada a respeito das práticas teatrais na aquisição/aprendizagem de línguas estrangeiras, tanto para instituições públicas como privadas. Orienta pesquisas sobre Linguage $(\mathrm{m} / \mathrm{ns})$ e Educação, com ênfase em Didática de Línguas Estrangeiras, desenvolvendo os seguintes temas: Arte-Educação, Teatro-Educação, Interfaces entre Língua e Literatura, Ensino-Aprendizagem de Línguas com Objetivos Acadêmicos e Profissionais. Na Extensão, dirigiu de agosto de 2011 a julho de 2015 o Centro Interdepartamental de Línguas da FFLCH-USP.

\section{OUTROS COLABORADORES DESTE NÚMERO}

\section{DÉBORAH ALVES MIRANDA}


Estudante de graduação em Letras -Língua Portuguesa e Língua Francesa pela Universidade Federal de Campina Grande. Atualmente participa do Programa de Monitoria do CH-UFCG como monitora da disciplina Sintaxe Interoracional

\section{JOSÉ RIBAMAR CAROLINO BEZERRA}

Possui graduação em Letras - Inglês pela Universidade Federal de Campina Grande (2009) e graduação em Licenciatura em Letras Língua Francesa pela Universidade Federal de Campina Grande (2003). Atualmente é Professor de ensino fundamental e médio da Escola Municipal de Ensino Fundamental e Médio Nila Ferreira. Tem experiência na área de Letras, com ênfase em Línguas Estrangeiras Modernas.

\section{NATHÁLIA NIELY TAVARES ALVES}

Graduanda do curso de Letras - Língua portuguesa na Universidade Federal de Campina Grande e bolsista no Programa de Educação Tutorial (PET) de Letras da UFCG. 